\title{
Total dose and frequency of administration critically affect success of nasal mucosal tolerance induction
}

\author{
Hui-Rong Jiang, Neil Taylor, Linda Duncan, Andrew D Dick, John V Forrester
}

\begin{abstract}
Aims-Nasal tolerance induction with autoantigens can effectively protect against a variety of experimental models of autoimmune disease. The aims of this study were to characterise the dosage and kinetics of inhibition of experimental autoimmune uveoretinitis (EAU) via intranasal administration of the uveitogenic antigen interphotoreceptor retinal binding protein (IRBP) in the murine model of IRBP induced EAU.

Methods-B10RIII mice were tolerised by intranasal administration of IRBP either with a long term multiple low dose or a short term/high dosing regimen before subcutaneous immunisation with IRBP in complete Freund's adjuvant (CFA). On day 15 post-immunisation, mice were killed and eyes were removed for histological examination and quantification of inflammatory cell infiltration and degree of target organ (rod outer segment, ROS) destruction.

Results-Nasal administration of multiple low doses of IRBP $(1 \mu \mathrm{g}$ or $3 \mu \mathrm{g}$ IRBP per mouse per day for 10 days) significantly protected mice from IRBP induced EAU. Short term/high dose regimens were only effective when given either as a single or, at most, as two consecutive doses $(40 \mu \mathrm{g}$ per dose). Multiple doses in the range of 45-120 $\mu \mathrm{g}$ over 3 days afforded no protection. Conclusions-These results indicate that both dose and frequency of intranasal antigen administration are pivotal to tolerance induction and subsequent suppression of $T$ cell mediated autoimmune disease.

(Br F Ophthalmol 2001;85:739-744)
\end{abstract}

Ophthalmology,

University of Aberdeen

Medical School

Foresterhill, Aberdeen

AB25 2ZD, UK

H-R Jiang

N Taylor

L Duncan

J V Forrester

Division of

Ophthalmology,

University of Bristol,

Bristol Eye Hospital,

Bristol BS1 2LX, UK

A D Dick

Correspondence to:

Professor John V Forrester

j.forrester@abdn.ac.uk

Accepted for publication

8 January 2001 of underlying immunological mechani furthermore for the development of novel therapeutic approaches. the neural retina. Although EAU can be induced by a variety of retinal antigens in cympathetic ophthalmia, sarcoid and birdshot retinochoroidopathy. ${ }^{2-4}$ As the close clinicopathological tion of EAU in mice to human PSII, the model
Experimental autoimmune uveitis (EAU) is a
Mucosal administration of autoantigens results in the development of a state of peripheral immunological tolerance. ${ }^{5}$ Mucosal tolerance induction by oral or nasal antigen administration of autoantigen effectively prevents several experimental disease models, including experimental autoimmune encephalomyelitis (EAE), experimental myasthenia gravis (EAMG), collagen induced arthritis (CIA), insulin dependent diabetes mellitus in the NOD mouse, and EAU. ${ }^{6-11}$ Despite such success, the results of trials in autoimmune diseases in humans are equivocal. For example, in both multiple sclerosis and uveitis administration of bovine myelin basic protein and retinal antigens, respectively, failed to show conclusively any clinical significant improvement. ${ }^{12}{ }^{13}$ This may have been due in part to our fundamental lack of understanding of the mechanisms of tolerance with regard to induction protocol, dosage, and frequency of therapy. To date several mechanisms of mucosal tolerance induction have been proposed, including $\mathrm{T}$ cell anergy, ${ }^{14}$ generation of regulatory Th3 (TGF- $\beta$ producing) cells, ${ }^{15}$ or CD8+ $\mathrm{T}$ cells ${ }^{11}{ }^{16}$ and $\gamma \delta \mathrm{T}$ cells, ${ }^{17}{ }^{18}$ all of which are dependent upon the dose and route of antigen delivery. ${ }^{19}$ Recent data have in part shifted emphasis towards the central role of CD4+ $\mathrm{T}$ cells and IL-2, ${ }^{20}$ including both peptide affinity for MHC class II binding ${ }^{22}$ as well as inherent hierarchical ability of $\mathrm{T}$ cell epitopes to induce tolerance. ${ }^{23}$ With respect to $\mathrm{CD} 4+\mathrm{T}$ cells, mucosal administration of autoantigen results in early activation and subsequent apoptosis of $\mathrm{T}$ cell populations. ${ }^{24-27}$ Studies of transgenic ( $\mathrm{Tg}$ ) mice have shown that the success of tolerance therapy is dependent upon the duration of therapy that in turn is dependent upon the precursor frequency of antigen specific $\mathrm{T}$ cells. ${ }^{28}$ In both Tg OVA and AC1-9TCR Tg mice following intranasal antigen delivery early activation followed by a transient and incomplete deletion of $\mathrm{T}$ cells was observed. Residual $\mathrm{T}$ cells remained unresponsive, although in the EAE model, they produced IL-10. ${ }^{28}$ Such results are comparable with our previous data in EAU in rat showing that, following intranasal retinal antigen delivery, lymph node cells were activated (IFN- $\gamma$ spurt) and on further antigen challenge increased levels of apoptosis were noted within the draining lymph node. ${ }^{26}$ Although regulatory cells were generated, tolerance could only be transferred via spleen cells. Moreover, the cells that did infiltrate the retina in tolerised animals produced IL-10. ${ }^{29}$ 
Although the precise mechanisms of nasal tolerance induction remain undefined the specific draining lymph nodes, which directly drain the nasal or oral mucosa, do constitute a unique microenvironment, without which tolerance induction is not possible. ${ }^{30}$

Mucosal tolerance is more effective following nasal administration compared with oral administration of antigens at the same dose. ${ }^{31}$ Following our previous observations of nasal tolerance with serial doses of intranasal retinal antigens in suppressing EAU in Lewis rat, ${ }^{32}$ the aims of the present work were to better characterise the dosage and kinetics of inhibition of IRBP induced EAU via intranasal IRBP administration in a murine model. ${ }^{33}$

\section{Materials and methods}

ANTIGEN

IRBP was prepared as previously described. ${ }^{34}$ Briefly, interphotoreceptor matrix was loaded onto a concanavalin-A (Con-A) sepharose affinity chromatography column (Pharmacia, Sweden) and crude IRBP eluted using TRIS$\mathrm{HCl} / 0.15 \mathrm{mM} \quad \mathrm{NaCl} / 1 \quad \mathrm{mM} \quad \mathrm{CaCl} / 1 \quad \mathrm{mM}$ $\mathrm{MnCl} / 0.2 \mathrm{mM}$ methyl-D-mannopyranoside, pH 7.5 (Sigma, UK). Further purification was achieved using a sepharose high performance chromatograph (Pharmacia) and mannose agarose affinity column (Sigma, UK) to remove contaminating ConA. The purified IRBP was dialysed against PBS and then the concentration of the IRBP was tested by Coomassie protein assay reagent (Pierce, UK). The purified IRBP produced a single band on SDS-PAGE and was aliquoted and stored at $-20^{\circ} \mathrm{C}$ before use.

ANIMALS

Inbred male B10RIII mice 8-12 weeks of age were obtained from the biological service unit at the medical school, University of Aberdeen. The procedures adopted conformed to the regulations of the Animal Licence Act (UK), and to the ARVO statement for the use of animals in ophthalmic and vision research.

INDUCTION OF NASAL TOLERANCE

(A) Multiple 10 day (2 week $\times 5)$ low dose tolerance induction regimen

Three groups of animals (with 10 mice in each group) were administered intranasally to a total dose of $30 \mu \mathrm{g}$ or $10 \mu \mathrm{g}$ IRBP over 10 daily applications within 2 weeks (day -21 to -10 ). Controls were simultaneously treated with phosphate buffered saline (PBS). All mice were immunised on day 0 with IRBP in CFA, and with additional pertussis toxin adjuvant (PTX) (see EAU induction).

(B) 1, 2, or 3 dose tolerance induction (varying total antigen dose)

Four groups of mice (eight mice in each group) were administered intranasally to a total of 120 $\mu \mathrm{g}$ IRBP per mouse over 3 days (from day -12 to -10 ), a total of $80 \mu \mathrm{g}$ IRBP per mouse over 2 days (day -11 and day -10 ), or a single dose of $40 \mu \mathrm{g}$ IRBP $($ day -10$)$. Controls received PBS and, following intranasal administration, all animals were challenged with IRBP in CFA and PTX 9 days later.

(C) 1,2, or 3 dose tolerance induction (total antigen dose constant)

Five groups of mice (six mice in each group) were administered intranasally to a total of 45 $\mu \mathrm{g}$ IRBP per mouse over 3 days (from day -12 to -10), a total of $45 \mu \mathrm{g}$ IRBP per mouse over 2 days (from day -11 to day -10 ), a single dose of $45 \mu \mathrm{g}$ IRBP per mouse, or PBS. All mice were then immunised with IRBP in CFA, and with additional PTX.

EAU INDUCTION AND DISEASE EVALUATION Mice were immunised subcutaneously with 100 $\mu \mathrm{g} / 50 \mu \mathrm{l}$ of IRBP emulsified with an equal volume of Freund's complete adjuvant $(\mathrm{CFA}<\mathrm{H} 37 \mathrm{R})$ (Difco Labs, USA). An additional intraperitoneal injection of $0.5 \mu \mathrm{g}$ purified Bordetella pertussis toxin (PTX; strain Wellcome 28) (Speywood, UK) in $250 \mu$ was given. At day 15 post-immunisation, mice were killed and their eyes were removed and processed as described below in each protocol. Mice from protocol (A) and (B) were killed by asphyxiation in carbon dioxide and their eyes were fixed in $2.5 \%$ buffered glutaraldehyde and embedded in resin for standard haematoxylin and eosin staining. Eyes from protocol (C) were immediately frozen in OCT and sectioned for conventional immunohistochemical staining with anti-CD45 (common leucocyte antigen, CLA, IBL-3/16, from Serotec) monoclonal antibody to detect infiltrating leucocytes within retina. The staining procedures were the same as described before. ${ }^{33}$ Since EAU severity of both eyes from each mouse was very similar only one eye (right eye) of each mouse was graded by independent observers. The intensity of uveoretinitis was evaluated with a slightly modified version of the customised histological grading system established in this laboratory for rat EAU. ${ }^{35}$ This grading system separately grades the degree of inflammatory cell infiltrate in various locations such as the retina, ciliary body, and anterior chamber, and the degree of standard retinal damage as evidenced by, for instance, loss of ROS, retinal folds, and retinal detachment. This allows the observers to differentiate between the inflammatory cell infiltrate and the structural damage to the retina/choroid since inflammatory cell infiltration does not always lead to retinal damage.

STATISTICAL ANALYSIS

Statistical analysis was performed using sPss software. Analysis of the EAU grades (nonparametric) was performed by Mann-Whitney. A $p$ value of $<0.05$ was considered statistically significant.

\section{Results}

MULTIPLE LOW DOSES OF IRBP INTRANASALLY PROTECT MICE AGAINST EAU

To investigate the effect of multiple low doses of IRBP on the development of IRBP induced B10RIII mice EAU, animals were treated with IRBP intranasally 10 days before immunisation at doses of $1 \mu \mathrm{g}$ and $3 \mu \mathrm{g}$ as described in 


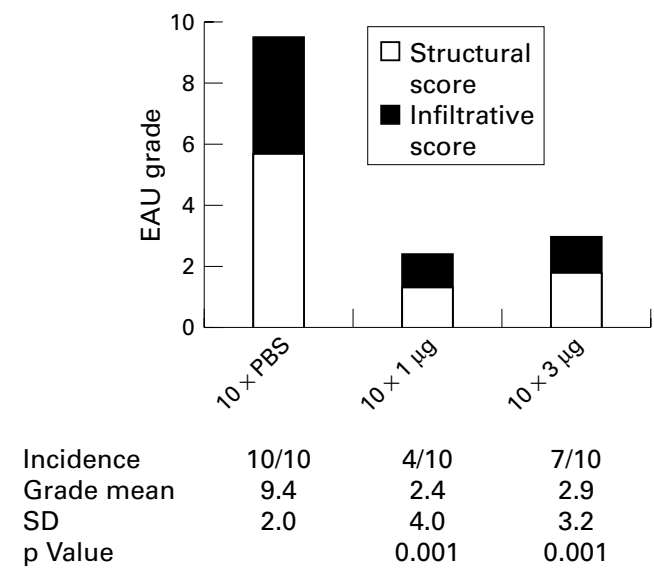

Figure 1 Multiple low dose intranasal administered IRBP suppresses IRBP induced EAU. EAU was markedly suppressed in tolerising a total of $10 \mu \mathrm{g}$ or $30 \mu \mathrm{g} I R B P$ administered intranasally over 10 days compared with the $P B S$ pretreated mice. Incidence (diseased/total mice), EAU histological grade mean (SD), and $p$ value between the antigen and PBS tolerised groups are detailed.

the Methods section. Control mice were given 10 doses of PBS on the same days. Nine days after completion of administration of antigen intranasally, all mice were challenged by immunising with a uveitogenic dose of IRBP. Ten animals in each group were tested. Figure 1 shows the incidence and mean severity grade (SD) of EAU. Eyes collected and processed on day 15 post-immunisation showed that mice that had received the lowest total dose of $10 \mu \mathrm{g}$ IRBP over 10 days displayed the greatest suppression of EAU (with 4/10 incidence and severity grade of 2.4) and protection against destruction compared with the control group (with 10/10 incidence and grade of 9.4) ( $\mathrm{p}=$ 0.001 ). Significant suppression of EAU was also observed in animals receiving a total dose of $30 \mu \mathrm{g}$ IRBP over 10 days (with $7 / 10$ incidence and EAU grade at 2.9). Thus, both the incidence and severity of EAU were

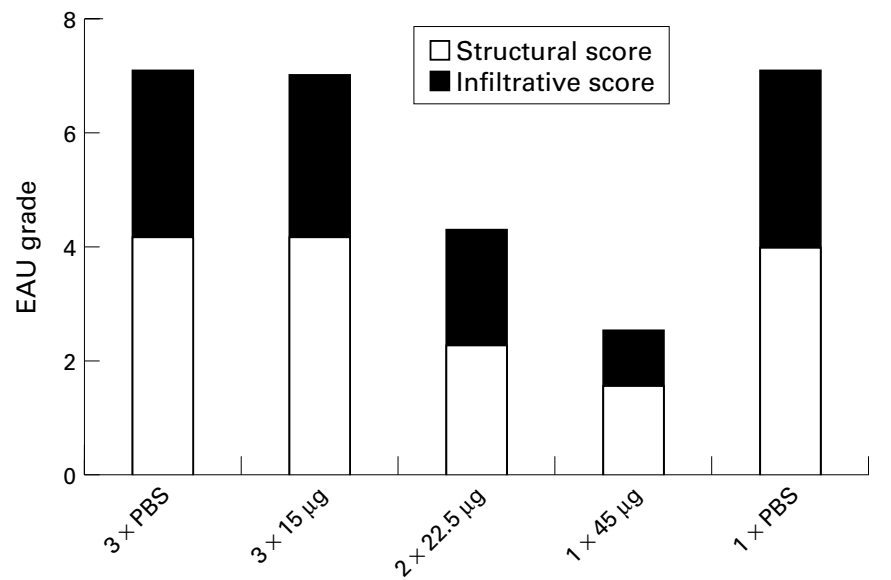

$\begin{array}{lccccc}\text { Incidence } & 6 / 6 & 6 / 6 & 6 / 6 & 5 / 6 & 6 / 6 \\ \text { Grade mean } & 7.0 & 6.8 & 4.3 & 2.5 & 7.0 \\ \text { SD } & 2.0 & 1.5 & 1.6 & 1.9 & 1.7 \\ \text { p Value } & & 0.67 & 0.03 & 0.008 & 0.68\end{array}$

Figure 3 Effect of frequency and dose delivery during tolerance induction. EAU was significantly suppressed by a total of $45 \mu \mathrm{g} I R B P$ in one or two doses. A total of $45 \mu \mathrm{g}$ IRBP intranasally administered over 3 days failed to protect against IRBP induced EAU. Incidence (diseased/total mice), EAU histological grade mean and SD, and $p$ value between the antigen and PBS tolerised groups are detailed.

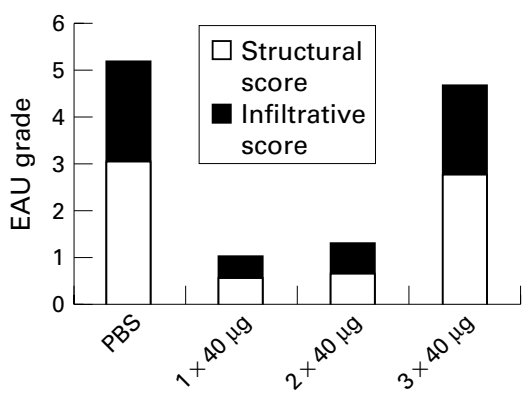

$\begin{array}{lcccc}\text { Incidence } & 7 / 8 & 2 / 8 & 3 / 8 & 6 / 8 \\ \text { Grade mean } & 5.2 & 1.0 & 1.3 & 4.7 \\ \text { SD } & 3.1 & 1.8 & 1.8 & 3.3 \\ \text { p Value } & & 0.008 & 0.011 & 0.833\end{array}$

Figure 2 A single high dose of intranasal IRBP is effective in protecting mice from EAU. EAU was suppressed significantly by a single intranasal dose of $40 \mu \mathrm{g}$ or two doses of $80 \mu \mathrm{g}$, but not by a total of $120 \mu \mathrm{g}$ IRBP administered intranasally over 3 days. Incidence (diseased/total mice), EAU histological grade mean and $S D$, and $p$ value between the antigen and PBS tolerised groups are detailed.

reduced markedly using this regime especially at the low dose of $1 \mu \mathrm{g}$ /day for 10 days.

ONE AND TWO, BUT NOT THREE "HIGH" CONSECUTIVE DOSES OF ANTIGEN INTRANASALLY ARE EFFECTIVE IN PREVENTING EAU

Both in the Lewis rat and, as this study shows, in murine EAU, multiple low doses of antigen by nasal administration are very effective in protecting animals from developing EAU and the effect is dose dependent. We therefore wished to investigate whether a single large dose of antigen could have the same effect as multiple small doses. In this part of the study eight animals in each group were studied. As shown in Figure 2, a single dose of $40 \mu \mathrm{g}$ of IRBP administered 10 days before challenge significantly inhibited disease severity (incidence $2 / 8$, grade 1.0 ). Two high doses (total $80 \mu \mathrm{g}$ IRBP) on successive days were also very effective in generating suppression of EAU (incidence 3/8, EAU grade 1.3). Increasing the dose to a total of $120 \mu \mathrm{g}$ IRBP over 3 consecutive days failed to induce tolerance and disease suppression (incidence $6 / 8$, grade 4.7 ). In this group, all mice developed severe EAU with marked target organ damage with no significant difference compared with the control group, which had an incidence of $7 / 8$ and EAU grade at 5.2.

FAILURE TO PREVENT EAU WITH THE THREE DOSES OF INTRANASAL IRBP DELIVERY IS NOT RELATED TO TOTAL ANTIGEN DOSE

As our previous experiments showed one dose but not three consecutive doses of $40 \mu \mathrm{g}$ protected against the development of target organ destruction in EAU. Experiments were then designed to determine whether protection was due to either the total amount of antigen administered or to the timing of antigen delivery. Five groups of mice ( $n=6$ in each group) were tolerised with either two or three consecutive doses of IRBP or a single delivery of antigen. All test groups received a total dose of $45 \mu \mathrm{g} \mathrm{IRBP} / \mathrm{mouse}$ or equivalent volume of PBS in controls. As shown in Figure 3, which 

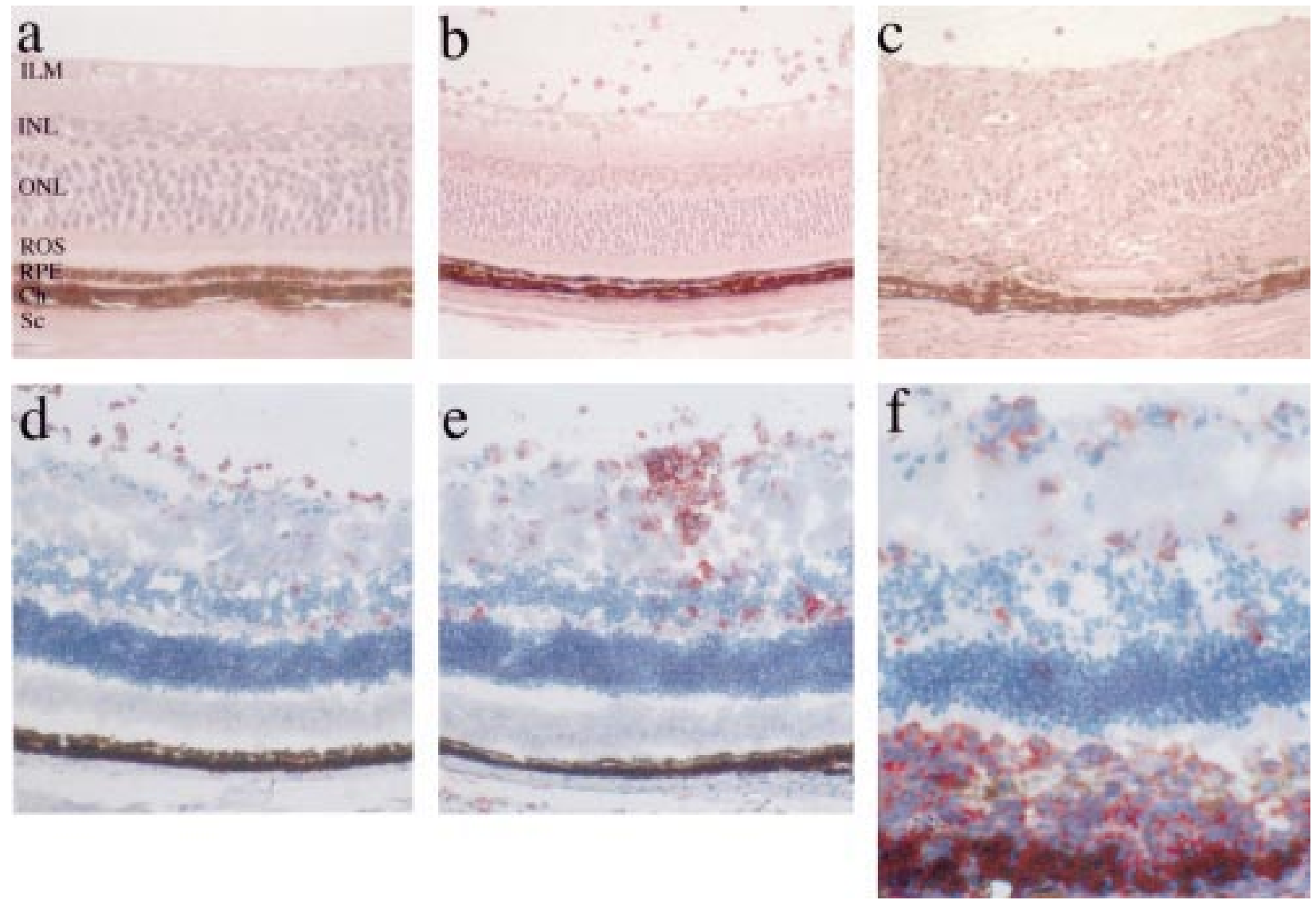

Figure 4 Histological and immunohistochemical analysis of retina from tolerised and control animals in IRBP induced EAU. (a) Normal retina structure from a mouse that received a total of $10 \mu \mathrm{g}$ of IRBP intranasally before immunisation. ILM = inner limiting membrane layer; INL = inner nuclear layer; $O N L=$ outer nuclear layer; $R O S=$ photoreceptor rod outer segment layer; RPE = retinal pigment epithelial cell layer; Ch = choroid; Sc = sclera.$(b)$ Retina from a mouse that received a total of $30 \mu \mathrm{g}$ of IRBP intranasally before immunisation. A large number of infiltrating cells were observed in the vitreous and inner layers of retina, but not in the ROS layer. (c) Retina from control mouse that received PBS intranasally before immunisation. There was a massive leucocyte infiltrate in all layers of retina, particularly within the ROS layer. The whole structure of retina was damaged with loss of ROS. (d) and (e) Immunohistochemical staining of CD45 positive cells within retina from animals that received a single dose of $40 \mu \mathrm{g}$ IRBP intranasally. Retina shows infiltrating leucocytes in the vitreous, some inner layers of retina (partially accounted for by activated microglia), but not in the ROS layer. ( $f$ ) CD45 positive leucocytes were found largely within the ROS layer, although there was an infiltrate within inner retina in a control mouse.

confirmed our previous experiments, animals that received a single intranasal antigen dose displayed greatest disease suppression (incidence $5 / 6$, grade 2.5 ), with fewest signs of inflammatory cell infiltrate or target organ destruction (ROS). Animals receiving $45 \mu \mathrm{g}$ of IRBP intranasally over 3 days were not protected (incidence 6/6, EAU grade 6.8).

INTRANASAL IRBP ADMINISTRATION INHIBITS BOTH THE INFLAMMATORY CELLS INFILTRATE AND TARGET TISSUE DAMAGE DURING EAU Intranasal administration of retinal antigen using either the long term/low dose or the short term/high dose regimen significantly suppressed target organ (ROS) damage. Representative histological appearances shown in Figure 4 document both significant reduction in leucocytic infiltration and structural retinal damage during IRBP induced EAU in tolerised animals. Mice pretreated with PBS developed severe EAU with marked damage to target organ ROS, and leucocytic infiltration including retinal vasculitis and perivasculitis, inflammatory cell infiltration within vitreous, and all layers of retina and choroid (Fig 4c). Frequently, the ROS layer was completely destroyed and heavily infiltrated with CD45+ leucocytes (Fig 4f), haemorrhage, and exudate.
In comparison, animals that had received multiple low tolerogenic doses of IRBP intranasally, showed reduced infiltrating leucocyte numbers concurrent with minimal ROS loss (Fig 4a and b). Immunohistochemical staining with CD45 in the "short term" tolerised mice showed a similar pattern of infiltrating cell distribution in vitreous, inner retinal layers but not in the target organ. In these animals, the ROS layer remained intact (Fig $4 \mathrm{~d}$ and e).

\section{Discussion}

Oral and nasal mucosal administration of antigen have been identified as a useful means to induce antigen specific immunological tolerance. However, tolerance induction is related to the route of antigen administration (oral, nasal, or parenteral), type of antigen (whole protein, peptide, or altered peptide), and timing with regard to disease onset. ${ }^{5}$ The possibility of enhancing rather than inhibiting immunity is also raised depending on the conditions prevailing while antigen is administered. The quantity of the administered antigen usually influences the tolerogenic effect, although no criterion of dose dependent effect of mucosal tolerance so far has been established in any animal or human trials. Our results show that intranasal inoculation with IRBP had different effects on murine 
IRBP induced EAU according to both dose and frequency of administration. Maximal inhibition of both the incidence and severity of EAU in IRBP induced B10RIII mice was noticed in those mice pretreated with multiple small doses (total $10 \mu \mathrm{g}$ ) of IRBP. This is in agreement with our previous data from the rat EAU model that showed suppression of EAU can be achieved by administering multiple low doses of retinal extract, S-Ag, or IRBP via the nasorespiratory tract. ${ }^{26}{ }^{35}$ However, Tsitoura et al reported that low doses such as $0.1 \mu \mathrm{g}$ administered intranasally over 3 days failed to downregulate $\mathrm{T}$ cell responsiveness. ${ }^{36}$ The importance of dose and dosing regimen is also recognised in oral tolerance $^{21}$ : feeding the antigen three times did not protect the mice against EAU while multiple feedings (five times) protected against disease induction. These results may indicate that in a low dose pretreatment regimen (10 days in our experiment), the dosage level is critical to achieve protection. The results of this and other studies suggest that long term/low dose regimen of intranasal administration of autoantigen is potentially a safe and effective route for antigen based immunotherapy for autoimmune disease.

With respect to manipulating dose, we observed that a single or at most two high doses of antigen were protective. This is in agreement with a study ${ }^{37}$ in a spontaneous insulin dependent diabetes murine model which showed that a single intranasal administration of $50 \mu \mathrm{g}$ GAD65 peptides induces a Th2 cell response that inhibited the spontaneous development of autoreactive Th1 responses and the progression of $\beta$ cell autoimmunity in NOD mice. However, our results also showed that multiple high doses (three doses) were ineffective in protecting against EAU. Moreover, it was the single administration of $45 \mu \mathrm{g}$, but not a total amount of $45 \mu \mathrm{g}$ ( $15 \mu \mathrm{g}$ per day) over 3 days that achieved protection in mice. One interpretation, therefore, is that not only the dose, but also the frequency of administration is critical to nasal mucosal tolerance induction. The therapeutic window is therefore small when using higher doses of antigen and may thus be a less successful approach when translated into clinical use.

The mechanisms by which mucosal tolerance is mediated are only partly understood. It is suggested that different mechanisms operate at different doses both in oral ${ }^{38}$ and nasal tolerance. ${ }^{39}$ Low dose tolerance is mediated by active suppression, while high doses of antigen tend to induce anergy or clonal deletion. Recently, controversial results regarding the function of Th3 $\mathrm{T}$ cells in mucosal tolerance have been reported. Baggi et al suggest that Th3 cells were not involved in oral tolerance induction, ${ }^{40}$ although this is in disagreement with other reports that show an induction of antigen specific TGF- $\beta$ producing $\mathrm{T}$ cells are involved in disease suppression. ${ }^{41}{ }^{42}$ There is further evidence from clinical observations in patients with multiple sclerosis that antigen specific TGF- $\beta 1$ secreting $T$ cells represent a distinct lineage of $\mathrm{T}$ cells that localise to the target organ and then suppress inflammation in the local microenvironment. ${ }^{43}$ In the present study, we attempted to use flow cytometry to detect the changes of activation markers on CD4 and CD8 T cells in the draining lymph nodes after a single intranasal antigen administration. A decrease in the proportion of CD4+CD62L+ and CD8+CD62+ (CD62L, L-selectin) cells in the draining lymph node was frequently detected hours and days after intranasal administered of antigens from regional lymph node (data not shown). CD62L downregulation, however, was not consistent and was transient. Herbelin et $a l^{44}$ have shown that TCR $\alpha \beta+\mathrm{CD} 4+$ thymocytes expressing L-selectin mediate active tolerance in the nonobese diabetic mouse. We were unable to determine consistent changes in CD62L expression following a single dose and found no relation with generation of regulatory CD 4+CD 45RB ${ }^{\text {low }} \mathrm{CD} 38+\mathrm{T}$ cells. ${ }^{45}$

It is generally believed that there is reciprocal inhibition of $\mathrm{Th} 1$ and $\mathrm{Th} 2$ response, and $\mathrm{Th} 2$ response exerts protective functions in Th1 mediated experimental models of autoimmune disease as both IL- 4 and IL-10 are required for the induction of mucosal tolerance. ${ }^{46}$ Our previous investigation in the rat EAU model with a long term regimen has demonstrated a reduced percentage of IFN- $\gamma+$ macrophages and CD4+ T cells with an increased percentage of IL-4+ or IL-10+ CD4+ T cells. ${ }^{29}$ Moreover, previous work has also shown transient $\mathrm{T}$ cell activation in the draining lymph nodes following the intranasal administration of retinal antigens, and that suppression of systemic Th1 responses is mediated by spleen regulatory cells during low dose tolerance therapy. ${ }^{26}$ Interestingly, a single high dose of antigen administered intranasally led to the induction of $\mathrm{Th} 2$ responses in the IDDM mouse model, and the adoptive co-transfer of splenic $\mathrm{T}$ cells from GAD64 peptide treated mice protects recipient NOD-scid/scid mice from IDDM. ${ }^{46}$ The two studies, by using different dose regimens for nasal tolerance in different autoimmune disease models, both showed the generation of Th2 cells and disease protection following transfer of splenocytes. One theory, therefore, is that multiple mechanisms are operative during high dose/short term and long term/low dose regimens so as to prevent the host from generating proinflammatory immunity to ingested antigen.

In conclusion, our results suggest that the effect of intranasal administration of autoantigens against autoimmune diseases is both dose and frequency dependent, and that successful tolerance induction is dependent upon route, antigen, species, and strain. These findings have important implications for the therapeutic applications of nasal tolerance in the clinic.

The authors would like to acknowledge funding from WH Ross Foundation for the Prevention of Blindness, Saving sight in Grampian Campaign, and the Development Trust of Aberdeen University.

1 Gery I, Mochizuki M, Nussenblatt RB. Retinal specific antigens and immunopathogenic processes they provoke. Prog Retinal Res 1986:75-109.

2 Forrester JV, Liversidge J, Dua HS, et al. Comparison of clinical and experimental uveitis. Curr Eye Res 1990;9 (Suppl):75-84.

3 Forrester JV. Uveitis: pathogenesis. Lancet 1991;338:1498501. 
4 Chan CC, Caspi, RR, Ni M, et al. Pathology of experimenal autoimmune uveoretinitis in mice $f$ Autoimmun 1990;3:247-55.

5 Xiao BB, Link H. Mucocal tolerance: a two-edged sword to prevent and treat autoimmune diseases. Clin Immuno Immunopathol 1997;85:119-28

6 Higgins PJ, Winer HL. Suppression of experimental autoimmune encephalomyelitis by oral administration of myelin basic protein and its fragment. F Immunol 1988;140: $440-5$.

7 Wang ZY, Qian J, Link H. Suppression of experimental autoimmune myasthenia gravis by oral administration of acetylcholine receptor. F Neuroimmunol 1993;44:209-14.

8 Ma CG, Zhang GX, Xiao BG, et al. Suppression of experimental autoimmune myasthenia gravis by nasal administration of acetylcholine receptor. $\mathcal{F}$ Neuroimmunol 1995;58: $51-60$

9 Zhang ZJ, Lee CSY, Lider O, et al. Suppression of adjuvant arthritis in Lewis rats by oral administration of type II colarthritis in Lewis rats by oral adminis

10 Daniel D, Wegmann DR. Protection of nonobese diabetic mice from diabetes by intranasal or subcutaneous adminismice from diabetes by intranasal or subcutaneous administraion of insulin pep

11 Nussenblatt RB, Caspi RR, Mahdi R, et al. Inhibition of $\mathrm{S}-\mathrm{Ag}$ induced experimental autoimmune uveoretinitis by oral induction of tolerance with S-Ag. F Immunol 1990;144: 1689-95.

12 Dick AD, Kreutzer B, Laliotou B, et al. Effects of mycophenolate mofetil on nasal mucosal tolerance induction. Invest Ophthalmol Vis Sci 1998;39:835-40.

13 Thurau SR, Chan CC, Nussenblatt RB, et al. Oral tolerance in a murine model of relapsing experimental autoimmune uveoretinitis (EAU): induction of protective tolerance in primed animals. Clin Exp Immunol 1997;109:370-6.

14 Melamed D, Friedman A. In vivo tolerisation of Th1 lymphocytes following a single feeding with ovalbumin: anergy in the absence of suppression. Eur f Immunol 1994; 24:1974-81.

15 Khoury SJ, Hancock WW, Weiner HL. Oral tolerance to myelin basic protein and and natural recovery from experimental autoimmune encephalomyelitis are associated with
down regulation of inflammatory cytokines and differential down regulation of inflammatory cytokines and differential upregulation of trnasforming growth factor beta, interleukin 4 and prostagland

Med 1992;176:1355-64.
16 Lider O, Santos LMB, S LCY, et al. Suppression of EAE by oral administration of myelin basic protein: suppression of the disease in in vitro immune responses is mediated by antigen-specific CD8+ cells. F Immunol 1998;142:748-53.

17 McMenamin C, Primm C, McKersey M, et al. Regulation of IgE responses to inhaled antigens in mice by antigen-
specific gamma delta T cells. Science 1993;265:1869-70.

18 Holt PG, Sly PD. Gammadelta T cells provide a breath of fresh air for asthma research. Nat Med 1999;5:1127-8.

19 Gregerson DS, Obstrisch WF, Donoso LA. Oral tolerance in experimental autoimmune uveoretinitis: distinct mechain experimental autoimmune uveoretinitis: distinct mecha-
nisms of resistance are induced by low zone versus high zone feeding protocols. F Immunol 1993;151:5751-61

20 Garside P, Steel M, Liew FY, et al. CD4+ but not CD8+ T cells are required for the induction of oral tolerance. Int cells are required for the

21 Rizzo LV, Miller-Rivero NE, Chan CC, et al. Interleukin-2 treatment potentiates induction of oral tolerance in a murine model of autoimmunity. F Clin Invest 1994;94: $1668-72$

22 Liu GY, Wraith DC. Affinity for Class II MHC determines the extent to which soluble peptides tolerize autoreactive T cells in naive and primed adult mice-implications for autoimmunity. Int Immunol 1995;7:1255-63.

23 Anderton SM, Wraith DC. Hierarchy in the ability of T cell epitopes to induce peripheral tolerance

myelin. Eur f Immunol 1998;28:1251-61.

Hoyne GF, Askonas BA, Hetzel C, et al. Regulation of house dust mite responses by intranasally administered peptide: transient activation of CD4+ T cells precedes the develop-
ment of tolerance in vivo. Int Immunol 1996;8:335-42.

25 Garside P, Steel M, Worthey EA, et al. Lymphocytes from orally tolerised mice display enhanced susceptibility to
death by apoptosis when cultured in the absence of antigen death by apoptosis when cultured in the
in vitro. Am f Pathol 1996;149:1971-9.

26 Laliotou B, Duncan L, Dick AD. Intranasal administration of retinal antigens induces transient $T$ cell activation and apoptosis within drainage lymph node but not spleen. $f$ Autoimmun 1999;12:145-55.
27 Marth T, Strober W, Kelsall BL. High dose oral tolerance in ovalbumin TCR-transgenic mice:systemic neutralization of IL-12 augments TGF-beta secreti

28 Burkhart C, Liu GY, Anderton SM, et al. Peptide-induced $\mathrm{T}$ cell regulation of experimental autoimmune encephalomyelitis: a role for IL-10. Int Immunol 1999;11: 1625-34.

29 Laliotou B, Dick AD. Modulating phenotype and cytokine production of leukocyte retinal infiltrate in experimental autoimmune uveoretintis following intranasal tolerance induction with retinal antigens. Br ₹ Ophthalmol 1999;83: $478-85$.

30 Wolvers DAW, Coenen-de Roo CJJ, Mebius RE, et al. Intranasally induced immunological tolerance is determined by characteristics of the draining lymph nodes: studies with OVA and human cartilage gp-39. F Immunol 1999;162: 1994-8.

31 Hirabayashi $\mathrm{T}$, Kurata $\mathrm{H}$, Funato $\mathrm{H}$, et al. Comparison of intranasal inoculation of influenza $\mathrm{HA}$ vaccine combined with cholera toxin $B$ subunit with oral or pareteral vaccinawith cholera toxin B subunit
tion. Vaccine $1990 ; 8: 243-8$.

32 Laliotou B, Liversidge J, Forrester JV, et al. Interphotoreceptor retinoid binding protein is a potent tolerogen in Lewis rat: suppression of experimental autoimmune uveoretinit is retinal antigen specific. Br $\mathcal{F}$ Ophthalmol 1997;81:1-7.

33 Jiang HR, Lumsden L, Forrester JV. Macrophages and dendritic cells in IRBP-induced experimental autoimmune uveoretinitis in B10RIII mice. Invest Ophthalmol Vis Sci 1999;40:3177-85

34 Harper FH, Liversidge J, Thomson AW, et al. Interphotoreceptor retinoid binding protein induced experimetnal autoimmune uveitis: an immunophenotypic analysis using alkaline phosphatase anti-alkaline phoaphatase staining, dual immunofluorescence and confocal microscopy. Curr Eye Res 1992;11 (Suppl):129-34

35 Dick $\mathrm{AD}$, Cheng YF, Liversidge J, et al. Immunomodulation of experimental autoimmune uveoretinitis: a model of tolerance induction with retinal antigens. Eye 1994;8:52-9.

36 Tsitoura DC, DeKruyff RH, Lamb JR, et al. Intranasal exposure to protein antigen induces immunological tolerance mediated by functionally disabled CD4+ T cells. $\mathcal{f}$ Immunol 1999;163:2592-600.

37 Tian J, Atkinson MA, Clare-Salzler M, et al. Nasal administration of glutamate decarboxylase (GAD65) peptides induces Th2 responses and prevents murine insulindependent diabetes. F Exp Med 1996;183:1561-7.

38 Chen Y, Inobe J, Marks R, Gommela P, et al. Peripheral deletion of antigen-reactive $\mathrm{T}$ cells in oral tolerance. Nature 1995;376:177-80.

39 Li HL, Liu JQ, Bai XF, et al. Dose-dependent mechanisms relate to nasal tolerance induction and protection against experimental autoimmune excephalomyelitis in Lewis rats. Immunology 1998;94:431-7.

40 Baggi F, Andreetta F, Caspani E, et al. Oral administration of an immunodominant T-cell epitope downregulates Th1/ Th2 cytokines and prevents experimental myasthenia gravis. $\mathcal{F}$ Clin Invest 1999;104:1287-95.

41 Shi FD, Li H, Wang H, et al. Mechanisms of nasal tolerance induction in experimental autoimmune myasthenia gravis: dentification of regulatory cells. F Immunol 1999;162: 5757-63.

42 Santos LM, al-Sabbagh A, Londono A, et al. Oral tolerance to myelin basic protein induces regulatory TGF-betasecreting T cells in Peyer's patches of SJL mice. Cell Immunol 1994;157:439-47.

43 Fukaura HF, Kent SC, Pietrusewicz MJ, et al. Induction of circulating myelin basic protein and proteolipid proteinspecific transforming growth factor- $\beta 1$-secreting Th3 T cells by oral administration of myelin in multiple sclerosis patients. F Clin Invest 1996;98:70-7.

44 Herbelin AH, Gombert JM, Lepault F, et al. Mature mainstream TCR $\alpha \beta+C D 4+$ thymocytes expressing L-selectin mediate 'active tolerance' in the nonobese diabetic mouse. F Immunol 1998;161:2620-8.

45 Powrie F, Carlino J, Leach MW, et al. A critical role for transforming growth factor- $\beta$ but not interleukin 4 in the suppression of $\mathrm{T}$ helper type 1-mediated colitis by CD45RB ${ }^{\text {low }} \mathrm{CD} 4+$ T cells. F Exp Med 1996;183:2669-74.

46 Rizzo LV, Morawetz RA, Miller-Rivero NE, et al. IL-4 and IL-10 are both required for the induction of oral tolerance. f Immunol 1999;162:2613-22 